\title{
The Impact of Knowledge Management on CRM Approaches
}

\author{
Fahed Al-Duwailah ${ }^{1, *} \&$ Tareq N. Hashem ${ }^{2}$ \\ ${ }^{1}$ National Security College, Kuwait \\ ${ }^{2}$ Marketing Department Isra University, Amman, Jordan \\ *Correspondence: National Security Collge, Kuwait. E-mail: duwailah@hotmail.com \\ Received: January 27, 2019 Accepted: March 18, $2019 \quad$ Online Published: April 2, 2019 \\ doi:10.5430/mos.v6n1p19 URL: https://doi.org/10.5430/mos.v6n1p19
}

\begin{abstract}
The purpose of the current paper is to examine the impact of knowledge management and its tools on the processes and approaches of the customer's relation management(CRM) within the banks sector in Kuwait.

The methodological approach followed in the current study is a quantitative. The population of the current study was all the CRM managers within the operating Kuwaiti banks which are working within the capital of Kuwait. The questionnaire was distributed on the sample of the study through visiting the banks and presenting the main aim of the paper. The convenience sample was (50) managers. However, the researchers retrieved (30) questionnaire forms (i.e. the response rate is $(60 \%)$.

The researchers found that there is a significant impact of knowledge management and its tools on processes and approaches of customer relation management within banks sector in Kuwait.
\end{abstract}

Keywords: knowledge management KM, Customer Relationship Management CRM, kuwait banks

\section{Introduction}

Ever since the appearance of organization; the flow of information has been processed in an informal way more than being formally managed. This process took place through the concept of trusting the performance of the employees and mitigating the culture of the organization along with the external environment. This was possible because of the small size that organizations used to be known with. However, with the increase in the global openness and the technological booming in our world is witnessing today and the increase in the competitiveness in the market in addition to the customer increasing awareness there has been a need to organize the process in which the flow of the information is streaming through. From that point, there appeared the concept of knowledge management which is considered to be a formal way to manage the flow of information that may appear within the organization (Bharadwaj et al, 2015; Choudhary, 2013).

\section{Literature Review}

Too much emphasis is being put lately on the approaches that CRM is following in managing the flow of customers within the banking sector. Basically, the banking sector is just like any other service sector, it continually comes up with new products and seeks to market these products on both level locally and internationally. The first step towards going through the idea of managing the customers flow within the banking sector starts by choosing the best and most suitable practices that guarantees full and vivid understanding of the degree of satisfaction that customers have towards the services and the products of a certain bank.

In a study by Rasoulinezhad (2011) which aimed at investigating the key procedures and advancements of knowledge management being utilized as a part of the business banks of Iran keeping in mind the end goal to give knowledge for investors and strategist to comprehend its significance. In the current developed time, information and the uses of it are the pith of associations for accomplishing contending advantage and characterized as another vital way to deal with advancement and a potential component for making bigger piece of the overall industry. Understanding knowledge management process as far as managing an account segment will highlight how it impacts authoritative execution. In a creating nation like Iran, it is additionally appearing indications of rivalry and enhanced 
approaches through knowledge management; however whether the knowledge management procedure is rehearsed in Iranian banks is still to be investigated.

\subsection{Knowledge Management}

Knowledge is presented as the most imperative property in the organization, and knowledge is for the most part known as "a discipline for identification, collection, organization, storage, sharing, and application of knowledge"(Akhavan, 2009). In the current aggressive environment, the components prompting endeavor achievement are no more essentially in the venture of capital, work, and crude material, yet in the capacity of learning advancement from every one of the individuals from an association. Knowledge management has secured an imperative position in this new period of aggressive business environment. As a result of this always expanding worldwide rivalry and change the customary authoritative administration is no more considered as a proper procedure. In 1993, Druker brought up that the idea of knowledge workers will have the most fundamental resource in a learning based economy and will appear as the main hotspot for upper hand. In the interim knowledge management has positive association with authoritative society. In this respect KM helps in the administration of data, learning, and skill through the KM process and utilizing the KM frameworks to be connected for this procedure can form a well-built managerial approach for organizations to follow in the path of building business and securing its approaches.

One of the most important success factors of money related foundations (Financial Institutions) is the viable and productive application, organization of data and information frameworks in the regions of operations, in addition to administration, bookkeeping and marketing. In any case, financial organizations must go after their survival through constant change and advancement to increase upper hand. The fiscal estimation of such ventures makes it basic for the FI's to utilize the right data framework and learning managerial framework. All through the world, FI's are turning out to be more reliant on data framework and innovation. Information has drastically changed the center of operations of business particularly the banking sector. The development of the knowledge management applications and tools has expanded the opposition among the banks which has lead to systems for consumer loyalty and human asset management enhancing (Attafar et al., 2013). In developing countries, it is additionally hinting at competition and developed information system. Sharing knowledge in financial institutions is very important and essential to ease the processes of associations and dealing with other parties within these facilities (Heczkova \& Stoklasa, 2011). The adjustment in the worldwide focused business environment has constrained banks to rethink their services and products and made them investigate $\mathrm{Km}$ approaches with a specific end goal to enhance their competitive ability and performance. According to Dzinkowski (2001) there are two fundamental classifications of knowledge management activities in money related organizations, one is seen as a fundamental part of the general corporate methodology which expects to develop, concentrate, and employ the organization's knowledge to build shareholder esteem. The second highlights the concept of enhancing the knowledge needed to proceed with a particular business process and consequently enhancing proficiency. The performance of the organization depends on the fact that an organization has to understand the client's needs and expectations which can be reached through the applications of knowledge management. According to Saber and Islami (2015) these days, there is a developing acknowledgment in the business scheme about the significance of knowledge as a basic asset for organizations. With the move from a conventional that is built on knowledge based economy learning has gotten to be one of the hidden resources of the organizations and its administration appears to be important. Consequently, the performance of organizations in the financial circle forms their capacity to apprehend, encode, and move of knowledge in a way more productive than their counterparts. on the same track, Chang and others (2014) stated Successful organizations make upper hand by diminishing control and expanding realizing which is gotten through creation and sharing of new knowledge constantly. So, associations and organizations these days are going through four main concepts which are:

- Efficiency

- Change

- Mission

- Competition

Knowledge management has the ability to enhances capacities of organizations and associations to do four specified ideas, we can say that Knowledge management is a precise way to deal with, form, get, sort out, access and utilization information and Knowledge in associations and organizations and its focal points in order to incorporate and enhance basic leadership, create more prominent adaptability, expanding benefits, diminishing hyperactivity, expanding efficiency, making new business opportunities, and decreasing cost, not to mention the influence of KM 
on the process of increasing the organization's market share and make the work environment healthier for employees. Globalization of trade and economy and the fierce competition has changed the role that a consumer may embrace in general. Nowadays, endeavors look clients not as a buyer. In today's focused world, clients are the prime interest of organizations and their fulfillment is the fundamental component in upper hand. Meeting clients' needs completely and recognizing their requests, desire and goals to purchase items are fundamental to fulfill them and organizations to increase upper hand ought to concentrate on clients and the meet their needs (Salar, 2012).

Marquardt, J. (2002) proposed a systemic approach to knowledge management processes in the Organization. The proposed model represents six steps to transfer knowledge to the user through the following steps in sequence:

1. Acquisition

2. Generation

3. Storage

4. Analysis and Data Mining

5. Transfer and Dissemination

6. Application and Validation

7. Revision of knowledge

\subsection{Definitions of Knowledge Management}

Recently, knowledge management appeared to be one of the most vital resources in organizations. it is considered as an approach that supports their continuous seeking for better performance and better competitive advantage. Knowledge management as an approach can be of great help for both governmental and non-governmental organizations. From one side, knowledge management helps organizations to perceive the way that people and human knowledge constitutes as a profitable resource of every organization and highlights the area of human knowledge to effectively contend and get by in today's unpredictable and element world like never before (Afrazeh, 2007). Specialists have given a wide range of definitions for knowledge management. As far as Pet rash, knowledge management is the process of gaining the suitable information from the suitable people at the correct time and the right place, with the goal that they can accomplish the objectives of the association to utilize information (Nabavi, 2006). Sivan (2001) defined KM as the art of performing knowledge-related actions from organizing, storing, collecting, sharing, disseminating and using knowledge elements consisting of data, information, experience, estimates, intellectual dimensions, judgments, intellectual initiatives. Whereas Levine (2001) defined it as a process through which information is generated as a result of multidimensional classifications of information in many different environments by multiple users

Davenport and Prusak (1998) considered that knowledge management or as it can be seen as the operation and advancement of an association's learning resources which can accomplish the objectives of the association. Serban and Luan (2002) state that knowledge management is a deliberate and composed methodology in associations with the goal that they can exploit both unequivocal and implicit learning and, which will prompt the creation of new information. (Serban \& Luan, 2002) Grodin (2006) trusts that knowledge management is information obtaining, learning creation and changing it into a usable structure, support and revelation and reuse it (Lytras et al., 2008).

From this point of view, knowledge management can be defined as "the systematic effort associated with knowledge management processes that involves the collection, classification, organization and storage of all types of direct and indirect knowledge and is ready for exchange among all employees in the organization, Level of decision-making efficiency".

\subsection{Customer Relationship Management}

Most of today's organizations believe that the idea of customer satisfaction is highly influential, so they claim to be customer-oriented in all their approaches and practice. According to Catalan-Matamoros (2012) CRM is a "combination of people, processes and technology that seeks to understand a company's customers". While Thompson and Nelson (2004) see that CRM is a "business strategy in which the outcomes optimize profitability, revenue, and customer satisfaction by organizing around customer segments, fostering customer satisfying behavior, and implementing customer-centered processes" (Thompson and Nelson, 2004. P.5). From Janjicek's perspective (2004), Customer Relationship Management is a philosophy that will put customers at the product design center and aim to guide and motivate the company's resources, efforts and resources to provide the best service and high customer loyalty. In terms of Lipscomb (2004), customer relationship management is the company's efforts in the 
field of creativity, innovation and development in order to enhance its relationship with its customers and thus gain their satisfaction and loyalty.

Goodhue et al. (2002) found that customer relationship management is a set of activities, efforts and programs that are adopted within the system to improve communication and dealing with customers by referring to the communication centers of the system such as technological tools or delegates that support the company to this goal, The company aims to reach customer satisfaction, increase product sales and increase revenues.

Kumar and Reinartz (2014) see that a customer oriented strategy is not seen to be a type of CRM unless the organization has the following set of characteristics which are:

- $\quad$ CRM has to be built in a $\mathrm{n}$ organization which values, believes and actions support the implementation of the CRM practices.

- The top management of the organization has to have the belief and the commitment towards the idea of the customer-oriented mission, and vision

- The organization has to be able to realize the heterogeneity and homogeneity of the customers in order to have the ability to treat them differently.

- The organization has to understand the long term revenue from customer's not only potential customers.

Ko (2008) pointed out that customer relationship management is a strategy that has a clear integration between its elements and aims to organize and manage customers in a specific way through which products and services are presented in a manner that suits the expectations and expectations of customers which will increase their satisfaction

\subsection{Customer Relationship Management (CRM) and Knowledge Management (KM)}

With the continuous development in the world of business and marketing; there has appeared a critical awareness concerning the importance of the clients and the clients" satisfaction. Among these developments is the appearance of the concept of Customer Relationship Management (CRM). CRM is a strategy that focuses on the customer a one of the revenue derivatives in an organization. According to Lawson-Body \& Limayem (2006) the main seven components of CRM are: customer prospecting, relations with customers, interactive management, understanding customer expectations, empowerment, partnerships, and personalization. Working on each one of these components can highly influence the process of applying CRM practices and at the same time increase the level of customer satisfaction.

In a study by Awwad and Al-Adaileh (2012) on the most influential practices of CRM in the context of Jordanian banks the authors aimed at understanding the factors that influence the application of CRM within the Jordanian commercial banks through distributing 400 questionnaires on different operating banks in Jordan it was found out that 5 out of 7 factors influenced the application of the CRM practices in Jordan these factors included interactive management, customers prospecting, customer surveying, responsiveness to customers, and partnerships respectively.

The first appearance of the term "Customer relationship management" was in the field of information technology (IT) in the mid 1990s. Generally, CRM depicts innovation based client arrangements (Maroofi and Deghani, 2013). From a marketing point of view, it can be said that CRM is a strategic approach that is concerned with making enhanced shareholder esteem through the advancement of suitable associations with key clients and client fragments. According to Swift (200) CRM is defined as "a method of understanding the customer behavior through intense communication with him/her to improve the performance which is represented in attracting the customer, keeping him/her and increasing his/her loyalty and profitability" (Soliman, 2011;p. 167). While Rababah and others (2011) saw CRM as business process that is " macro-level or highly aggregated process that subsumes numerous sub-processes, such as prospect identification and customer knowledge creation". As a technology, "CRM is an enabling technology for organizations to foster closer relationships with their customers" (Rababah et al, 2011. P. 22). Veber (2009) mentioned that CRM has many phases, among them:

1- Pre-pre-CRM stage: this refers to the stage where the organization is ready to serve customers, and have the basic needs and requirements for that issue

2- Pre-CRM stage: in this stage there appears the sales department which takes the initiatives of the marketing plans and strategies.

3- Basis for CRM: in this stage the marketing plans are concentrating on the marketing and promoting of the product/service 
4- $1^{\text {st }}$ CRM stage: This refers to the stage of starting to evaluate the degree of satisfaction that customers have

5- Second CRM stage: this is the proactive stage where the company manages to create a good relationship with the company and the organization is enjoying the relations that are being established through the CRM programs.

Customer relationship management consists of many measurements that are seen to be forming the overall core of the CRM applications and tools. The following figure highlights the components of the CRM:

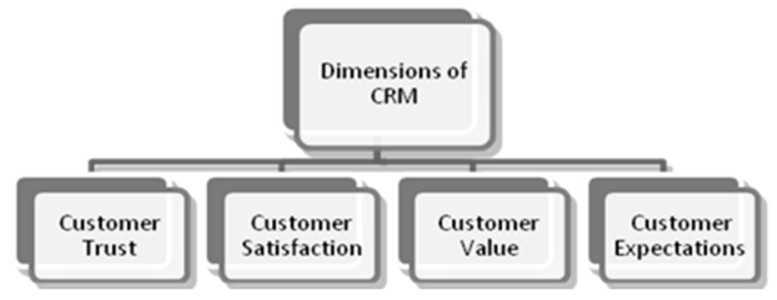

Figure 1. CRM Dimensions (Saber \& Islami, 2015)

According to the previous mentioned figure, the dimensions of CRM have a lot to do with the customers in general. It mainly focuses on the perceptions that may increase the level of satisfaction among individuals who are willing to enhance the level of the customer satisfaction. From that point, it can be seen that the most influential factors of the CRM dimensions are trust, satisfaction, value, and expectations. The relationship between learning administration and CRM at banking sector according to Saber and Islami (2015) developing CRM helps in the case of setting a well-built marketing plans through focusing and knowing more about the customer.

\section{Methodology}

One of the approaches that this paper suggests is to have an influence on CRM within a bank is the knowledge management practices and how it can have an influence on managing the customer's relationship to the bank.

\subsection{Purpose}

It is widely known that both knowledge management and customer relations management are seen to be a totally separated disciplines (Thomas, 2012). According to Jarvenpaa (2002), the two paths may share the same data warehouse and processes but at the same time they are different fields of interest with different orientations and tendencies. However, one can't deny that both fields are meant to improve the business efficiency and effectiveness on both external and internal levels in a way that supports the internal environment that the business processes are taking place and the external environment in which the results of the business processes will appear.

The purpose of the current paper is to examine the impact of knowledge management and its tools on the processes and approaches of the customer relation management within the banks sector in Kuwait.

\subsection{Design/Methodology/Approach}

The methodological approach followed in the current study is a quantitative approach, the data was gathered from two main sources of information, the first source was books, journals and e-journals, articles and reports. While the second set of data was approachable through the tool and the sample of the study. In order to generate data for the sake of answering the study's questions, a self-administered questionnaire was built and distributed on a sample of CRM managers in a chosen set of operating banks in Kuwait. The convenience sample was (50) managers. However, the researchers retrieved (30) questionnaire forms (i.e. the response rate is $(60 \%)$.

\subsection{Variables of the Study}

The variables of the study were formed through taking into account the tools of $\mathrm{KM}$ and examining its influence on the intensity of CRM in the organizations. The variables were as follows:

KM variables

$$
\begin{array}{ll}
\text { - } & \text { KM strategies } \\
\text { - } & \text { Corporate policies }
\end{array}
$$


- $\quad$ Organization's processes

- Management

- Technology

\subsection{Questions of the Study}

The main question of the current research study was:

To what extent do knowledge management tools influence the intensity of CRM approaches in organizations?

From the above question appear the sub-questions which are:

- In what way does KM appear in the field of CRM?

- What is the most influential KM tool on the CRM success within an organization?

- To what extent organizations are convinced with the relation between KM and CRM?

\subsection{Hypotheses of the Study}

The following set of hypotheses was processed through the methodological approach of the current study:

The main hypotheses:

There is a statistically significant influence of KM on CRM within the banking sector.

The sub-hypotheses:

H01: there is no statistically significant influence of knowledge management strategies on CRM approaches

H02: there is no statistically significant influence of corporate strategies on CRM approaches

$\mathbf{H 0}_{3}$ : there is no statistically significant influence of organization's processes on CRM approaches

$\mathrm{HO}_{4}$ : there is no statistically significant influence of management style on CRM approaches

H05: there is no statistically significant influence of technological aspects in an organization on CRM approaches

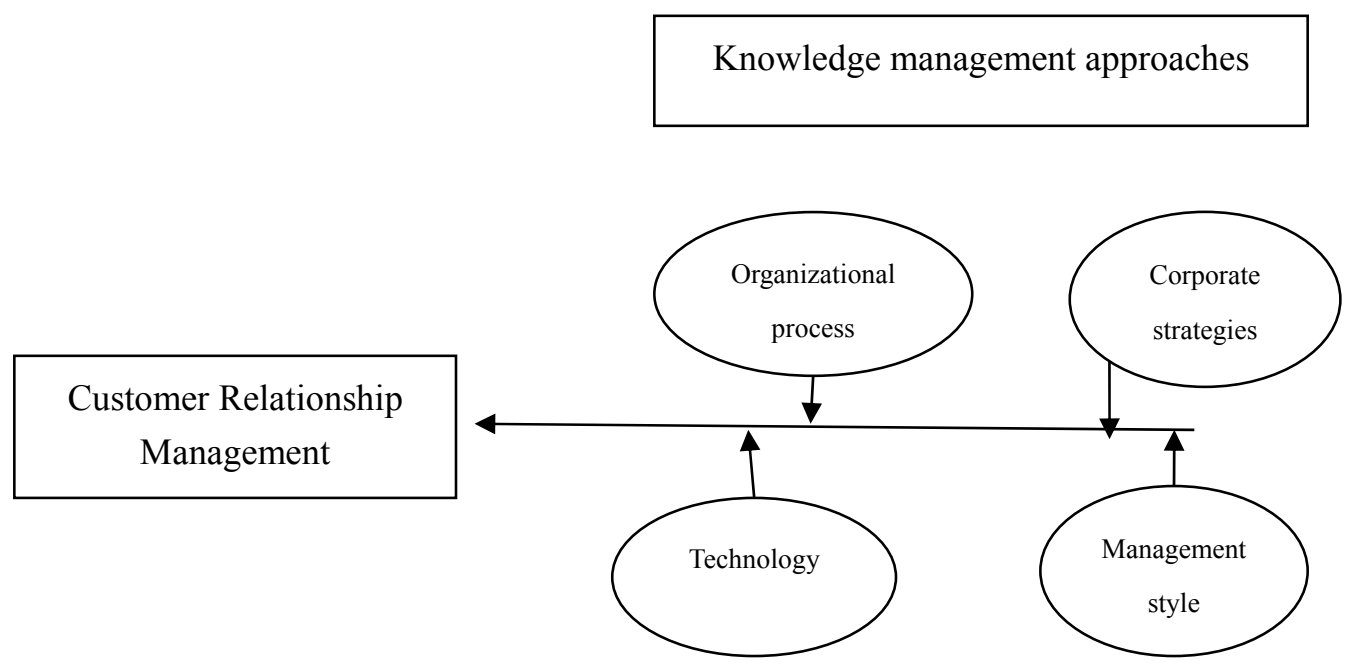

Figure 2. Study Model

\subsection{Research Implications}

It is expected from the current research to form a type of an indicative approach to the degree of influence that KM has on CRM within Kuwaiti banking sector.

In addition to that, it is expected from the current research to present the following:

- $\quad$ Generate new approaches of knowledge management strategies for organization specifically banks to employ within the internal processes of an organization. 
- Help in locating and identifying any malfunction in the current KM strategies within the bank which has a direct contact with CRM

- Highlight the role of KM tools in the field of CRM

- Develop a structure for CRM that is based on KM approaches and connect it to the risk management approaches as well.

\subsection{Sample}

The population of the current study was all the CRM managers within the operating Kuwaiti banks which are working within the capital of Kuwait through the year 2016. The used sample was a questionnaire bearing in mind that the nature of the research was quantitative in its approach in answering the questions of the study. The questionnaire was distributed on the sample of the study through visiting the banks and presenting the main aim of the paper.

\section{Analysis and Discussion}

The following section presents the analysis of the research tool after gathering the needed data and processing it through SPSS. The current section consists of two sections, the first presents the demographic variables analysis of the sample of the study, while the other section presents the analysis of the questionnaire paragraph based on the responses of the sample of the study.

\subsection{Demographic Variables}

Frequency and percentage have been computed for the sample characteristics.

\section{- Gender}

Table 1. Sample Distribution According to Gender

\begin{tabular}{lll}
\hline & Frequency & Percent \\
\hline Male & 23 & 76.7 \\
Female & 7 & 23.3 \\
Total & 30 & 100.0 \\
\hline
\end{tabular}

The above table shows that $76.7 \%$ of the sample was males while the rest was females with a percentage of $23.3 \%$ which shows that the percentage of males responding to the questionnaire was higher than the female respondents.

\section{- Job title}

Table 2. Sample Distribution According to Job Title

\begin{tabular}{lll}
\hline & Frequency & Percent \\
\hline Customer relation management & 12 & 40.0 \\
Public relations management & 6 & 20.0 \\
Operation Management & - & - \\
IT Management & 6 & 20.0 \\
Other (marketing and products) & 6 & 20.0 \\
Total & 30 & 100.0 \\
\hline
\end{tabular}

As for the table above, it shows the distribution of the sample according to their job title. In the above table (2) the results show that the highest percentage of the questionnaire respondents were for the benefit of CRM managers which are logical results concerning the fact that the most interested responses in answering the questionnaire paragraphs were the CRM managers who are known to be more involved in the process of gathering and benefiting from the applications of knowledge management in relation to CRM. As for the rest of the sample, it appeared that PR managers, operations managers and other managers answered equally to the questionnaire.

\section{- Academic qualification}


Table 3. Sample's Distribution According to Educational Level

\begin{tabular}{llc}
\hline & Frequency & Percent \\
\hline Diploma & 5 & 16.7 \\
Bachelors & 17 & 56.7 \\
Post graduate studies & 8 & 26.7 \\
Total & 30 & 100.0 \\
\hline
\end{tabular}

The above table (3) indicates that more than half of the sample is individuals with bachelor degree with a percentage of $56.7 \%$ of the sample and the least percentage was for individuals with Diploma degree. The most influential percentages of academic qualifications were of those who had the bachelor and the post graduates degrees indicating for the nature of employing, and recruiting within banks in Kuwait.

\section{- Experience}

Table 4. Sample Distribution According to Experience

\begin{tabular}{lll}
\hline & Frequency & Percent \\
\hline $5-10$ years & 6 & 20.0 \\
$11-15$ years & 6 & 20.0 \\
More than 16 years & 18 & 60.0 \\
Total & 30 & 100.0 \\
\hline
\end{tabular}

As it can be seen from the above table (4), it indicates that $60 \%$ of the sample has experience more than 16 years, which can be reasonable bearing in mind that the nature of the questionnaire and the paragraphs which were available within the tool needed to be answered by individuals who enjoyed a high level of experience in the field and who might be able to answer the questions based on actual experiences within the field of interest.

\subsection{Analysis of the Variables}

The current section presents the analysis and mean and standard deviation that are used to describe attitudes toward the variables of the study.

Table 5. Mean and Standard Deviation of the Study Variables

\begin{tabular}{lll}
\hline & Mean & Std. Deviation \\
\hline Knowledge Management Strategies and CRM & 3.7000 & .57135 \\
Corporate Policies & 3.6267 & .56013 \\
Organization's processes & 3.7200 & .47445 \\
management & 4.0857 & .54054 \\
Technology & 3.7429 & .58530 \\
\hline
\end{tabular}

Examining the above table (5), it can be seen that there is a positive attitude from participants towards the variables of the study. This appeared through the mean of the variables which scored higher than 3.00 referring to the variable as a good indicator. The most influential variable of the first variable was the (management) variable with a mean of (4.0857). Based on the analysis of the questionnaire, it appeared that the most influential variable which was taken into consideration was the variable related the management style, in another meaning, the analysis of the questionnaire shows that the management style has the most powerful influence that is related to the impact of KM on CRM in the banking sector. This also appeared in a study by Allameh and others (2012) stating that the managerial style that is being adopted in the organization can highly influence the space of freedom that KM plays and hence support the practices that are being used within the CRM applications and tool. This can be true to a certain extent which is related to the concept of understanding the role that KM has within the organizational activities that take place in financial institutions. Following the variables of management style there appeared the variable of technology which ranked in the second place and managed to get a score of 3.74 among the other variable coming after the variable of management. This result is also seen to be logical considering that technology is seen to be of great importance in today's business world and it has the power to manipulate and interfere in the activities and 
processes that are present and continues to appear within the financial institutions. In the third rank of the influential variable which effected the application of CRM tools and practices was the organization's process, meaning the internal processes that take place inside the organizational and which influence the degree of ease that a certain application may face during the phases of applying it. This variable scored 3.72 point stating that these organizational processes highly influence the development and the sharing of the knowledge and information distribution among the organization. On the same track came Bohari (2011) who stated that the organization's adopted plans, strategies, believes and visions are nothing more than the constituents of the internal processes that take place within an organization, in addition to the activities that are applied on the employees in terms of the nature of training that they get in relation to the customers relations and satisfaction.

\subsection{Hypotheses Testing}

\subsubsection{The Main Hypotheses}

There is a statistically significant impact of knowledge management on CRM approaches within the banking sector.

Multiple regression test is used to test the effect of the independent variables on the dependent variable.

It is found that $\mathrm{R}(0.946)$ is the correlation of the independent variables and the dependent variable.

Also it is found that $\mathrm{R}$ Square (0.895), which is the explained variance, is actually the square of the multiple $\mathrm{R}$ (0.946)2. What the results mean is that $(89.5 \%)$ of the variance (R-Square) in the dependent variable has been significantly explained by the independent variables.

Table 6. Hypotheses Testing

\begin{tabular}{lllll}
\hline \multicolumn{4}{c}{ Model Summary } \\
\hline Model & $\mathrm{R}$ & R Square & Adjusted R Square & Std. Error of the Estimate \\
1 & .946 & .895 & .878 & .19973 \\
\hline
\end{tabular}

\begin{tabular}{lllllll}
\hline \multicolumn{7}{c}{ ANOVA $^{\mathbf{a}}$} \\
\hline Model & & Sum of Squares & $\mathrm{df}$ & Mean Square & $\mathrm{F}$ & Sig. \\
\hline 1 & Regression & 8.469 & 4 & 2.117 & 53.074 & $.000^{\mathrm{b}}$ \\
& Residual & .997 & 25 & .040 & & \\
& Total & 9.467 & 29 & & & \\
\hline
\end{tabular}

The ANOVA table shows that the F value of (53.074) is significant at (0.05) level. Thus, there is significant effect between the independent variables and the dependent variable.

Table 7. Coefficient Table

\begin{tabular}{lllllll}
\hline \multirow{2}{*}{ Model } & & \multicolumn{2}{l}{$\begin{array}{l}\text { Unstandardized } \\
\text { Coefficients }\end{array}$} & \multicolumn{2}{l}{$\begin{array}{l}\text { Standardized } \\
\text { Coefficients }\end{array}$} & \multirow{2}{*}{ Sig. } \\
\cline { 3 - 5 } & & $\mathrm{B}$ & Std. Error & Beta & & \\
\hline 1 & (Constant) & -.287 & .365 & & -.786 & .439 \\
& policies & -.198 & .091 & -.194 & -2.171 & .040 \\
& process & .332 & .121 & .276 & 2.753 & .011 \\
& management & .313 & .125 & .296 & 2.498 & .019 \\
& Technology & .585 & .147 & .599 & 3.984 & .001 \\
\hline
\end{tabular}

Also according to the coefficient table it is found that t-value for each independent variable (Organizational Management Structure, Organization Culture, and Funding) is significant at 0.05 levels, that means:

1. There is a statistically significant influence of Corporate Policies on CRM approaches

2. There is a statistically significant influence of organization's processes on CRM approaches

3. There is a statistically significant influence of management style on CRM approaches 
4. There is a statistically significant influence of technological aspects in an organization on CRM approaches

Also it is found that technological aspects in an organization have the highest effect on CRM approaches. These results match with results of (Awwad and Al-Adaileh ,2012;Veber ,2009;Lawson-Body \& Limayem ,2006)

\subsection{Reliability Test}

A reliability test was carried out using Cronbachs' alpha, The results showed a value of (0.943) for the all items as well as alpha for each variable is greater than accepted percent 0.60 , which is a reasonable value indicating that the tool consistency that enhanced its use for the study.

\section{Conclusion}

Based on the analysis which was presented in the previous section, in accordance with the fact that all of the variables of $\mathrm{KM}$ were accepted to be influential on the CRM applications, processes and practices within the financial institutions the current research reached the following conclusion:

- The well-built use of the KM applications and tools give the experts and concerned parties in the financial institutions the needed help to use the information that are available between their hands which enable them to gain more knowledge about the nature of their customers, their needs, expectations and degree of satisfaction, this result matches with the study of (Rasoulinezhad, 2011; Attafar, et al., 2013)

- Among the most important factors that can deeply influence the successful application of CRM tools within the scope of KM is technology. Technology was found to be the most important element that plays a huge role in succeeding to the results that are supposed to be reached for through CRM, these results revolve around the nature of the current customers, the possible ways to attract more potential customers and the most efficient procedures that needs to be taken into consideration in order to reach well-built plans for marketing strategies.

- What was seen to be very beneficial about $\mathrm{Km}$ in CRM is the fact that it turns information about customers into knowledge about customers, which in its turn gives the organization the upper hand in controlling the losses and gains of the clients and gives it also the ability to focus on the weak points in order to strengthen them and present its services and products in a more suitable way.

- KM applications within the scope of CRM gives the institutions the chance to increase their profit margin through attracting more customers reaching the stage of valuable customers who were reached through the knowledge which was presented about them.

- Among the weak points which can negatively influence the application is the lack of technology and the weak managerial style, in addition to the poor communications.

- KM applications in CRM within financial institutions focus on the source of the knowledge rather than its nature, in another meaning, KM gets the information from the customers themselves not about them which present more precise and intact information about the next step that the organizations has to initiate.

- Knowledge management in its natural existence in an organization revolves around presenting knowledge about the organization which will aid in the process of mitigating any problems and give information about the nature of the activities that are being tackled within. When it comes to the field of CRM, the nature of knowledge management turn into the customer 's knowledge considering that it presents information about the customers and tries to tackle each and every activity related to customers in terms of keeping the current and attracting potentials.

\section{Recommendations}

Strengthening the relationship between knowledge management and CRM is something that is seen to be of great importance. It helps in giving more precise information and knowledge about the field of customers within the organizations specifically within the financial institution bearing in mind that this kind of institutions requires a great amount of trust and loyalty from both sides as it has to do with something that is really sensitive among people which is money. 
As it was reached through the current research study, the management style and technological aspects appeared to be the most influential schemes that can influence the applications of KM on CRM. Based on the argument, the author recommends the following:

- Run more research papers concerning the influence of KM approaches on the development and the results of the risk management strategies within financial organizations. Since Km gives information and knowledge about the institution then it is expected that it can form a helping approach to the strategies and plans initiated by risk management. It can appear through an application or a software that can gather all the needed data, analyze it and refer to a current or expected risk that may appear in the horizon, it can be a kind of a danger alarm or the institution.

- In addition, the author recommends initiating a study that has the ability to measure the gap between what is expected and what is perceived in the services and products among customers and compare the results between the financial institutions which run KM approaches and others which do not run any KM approaches in order to find out the real influence on the customer satisfaction in that scheme.

\section{References}

Allameh, S., Shahin, A., \& Tabanifar, B. (2011). Analysis of Relationship between Knowledge Management and Customer Relationship Management with Customer Knowledge Management (Case Study At Azaran Valve Co.). International Journal of Academic Research in Business and Social Sciences, 2(10), 65-77.

Attafar, A., Sadidi, M., Attafar, H., \& Shahin, A. (2013). The Role of Customer Knowledge Management (CKM)in Improving Organization-Customer Relationship. Middle East Journal of Scientific Research, 13(6), 829-835.

Bohari, A. (2011). The Influence of Customer Knowledge on CRM Performance of Malaysian ICT Companies: A Structural Equation Modeling Approach. International Journal of Business and Management, 6(7), 181-198.

Choudhary, A., Harding, J., Camarinha, M., Lenny, K., \& Tiwari, M. (2013). Knowledge management and supporting tools for collaborative networks. International Journal of Production Research, 51(7), 1953-1957. https://doi.org/10.1080/00207543.2012.758508

Goodhue, D., Wixom, B., \& Watson, H. (2002). Realizing Business Benefits Through CRM: Hitting the Right Target in the Right Way. MIS Quarterly Executive, 1(2), 79-96.

Heczkova, M., \& Stoklasa, M. (2011). Customer Relationship Management - Theory and Principles. Acta academica karviniensia, 11(4), 80-91. https://doi.org/10.25142/aak.2011.074

Janjicek R. (2004). "CRM architecture for enterprise relationship management in the millennium " a technical white paper by CHP. Retrieved from www.looksmark.com

Jarvenpaa, E., \& Maki, E. (2002). Knowledge management and customer relationship management: management of

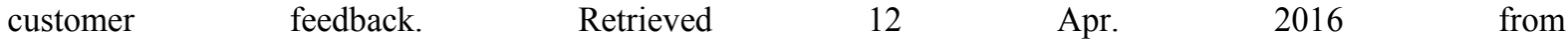
http://apollon1.alba.edu.gr/OKLC2002/Proceedings/pdf_files/ID358.pdf

Ko, E. (2008). Organizational characteristics and the CRM adoption process. Journal of Business Research, 61(1), 65-74. https://doi.org/10.1016/j.jbusres.2006.05.011

Levine, L. (2001). Integrating knowledge and Processes in a Learning Organization. Information Systems Management, 18(1), 21-33. https://doi.org/10.1201/1078/43194.18.1.20010101/31262.4

Lipscomb, D. (2004). Making the Case for Customer Relationship Management. CRM Guru, April 12, 2004.

Maroofi, F., \& Deghani, M. (2013). the effect of knowledge management on crm prosperperity. International Journal of R esearch In Social Sciences, 3(3), 75-86.

Marquardt, J. (2002). Building the Learning Organization. U.S.A., Davis - Black publishing Company.

Rababah, K., Mohd, H., \& Ibrahim, H. (2011). Customer Relationship Management (CRM) Processes from Theory to Practice: The Pre-implementation Plan of CRM System. International Journal of e-Education, e-Business, e-Management and e-Learning, 1(1), 22-27.

Rasoulinezhad, E. (2011). Measuring the Role of Knowledge Management Processes in the Commercial Banks of Iran. The Electronic Journal of Knowledge Management, 9(4), 353-364. 
Saber, M., \& Eslami, S. (2015). Investigate the Effect of Knowledge Management on Customer Relationship Management (Case Study: Mellat Bank, Yazd City). J. Appl. Environ. Biol. Sci, 5(11), 151-160.

Sivan, Y. Y. (2001). "Nine Keys To Acknowledge infrastructure: A proposed Analytic Framework For Organizational Knowledge management", center For Information Policy research, Harvard University.

Soliman, H. (2011). Customer Relationship Management and Its Relationship to the Marketing Performance. International Journal of Business and Social Science, 2(10), 166-182.

Thomas, D. (2015). The use of the intranet of the Durban University of Technology Library as a Knowledge Management tool. South African Journal of Libraries \& Information Science, 81(1), 21-7. https://doi.org/10.7553/81-1-1545 